\title{
What Drives the Structural Anchoring of ESD? Network Theory-Based Considerations
}

\author{
Anna-Luise Schönheit *, Ronald Gebauer and Dieter Rink
}

Citation: Schönheit, A.-L.;

Gebauer, R.; Rink, D.

What Drives the Structural

Anchoring of ESD? Network

Theory-Based Considerations.

Sustainability 2022, 14, 1761.

https://doi.org/10.3390/su14031761

Academic Editor:

Jordi Colomer Feliu

Received: 13 December 2021

Accepted: 31 January 2022

Published: 3 February 2022

Publisher's Note: MDPI stays neutral with regard to jurisdictional claims in published maps and institutional affiliations.

Copyright: () 2022 by the authors Licensee MDPI, Basel, Switzerland. This article is an open access article distributed under the terms and conditions of the Creative Commons Attribution (CC BY) license (https:// creativecommons.org/licenses/by/ $4.0 /)$.

\author{
Department of Urban and Environmental Sociology, Helmholtz Centre for Environmental Research-UFZ, \\ Permoserstraße 15, 04318 Leipzig, Germany; ronald.gebauer@ufz.de (R.G.); dieter.rink@ufz.de (D.R.) \\ * Correspondence: anna-luise.schoenheit@ufz.de
}

\begin{abstract}
The structural anchoring of Education for Sustainable Development (ESD) can be considered as a process of collective action. From a network theory perspective, the question arises as to which network structures promote the implementation of ESD in municipalities. Although network analysis has gained some attention in the research on ESD at a transregional level, it still lacks a theoretically grounded study at the municipal level. Against the background of corresponding theoretical and empirical contributions, we therefore present a derivation of relevant hypotheses. More specifically, argue that ESD is more likely to be implemented in municipal networks that feature medium density and intersectoral as well as intermunicipal bridges. Additionally, we assume that highly centralized municipal networks promote the structural anchoring of ESD in the initial phase, with decentralized structures being more conducive the more advanced the implementation. In other words, municipal structures which allow actors from various fields of action and municipalities to communicate with each other and exchange their specific ideas and experiences on a regular basis should foster ESD implementation. Furthermore, focal actors or fields of action may be advantageous for initiating ESD implementation in a municipality, but should lose significance as adaptation processes increase over time.
\end{abstract}

Keywords: Education for Sustainable Development; structural anchoring; municipalities; collective action; network theory

\section{Introduction}

As already highlighted in the global political program on Education for Sustainable Development (ESD) over the course of time, the implementation of ESD depends on the design and extent of collaboration of various institutions organizing and providing education at a local level (see, e.g., [1-4]). This perspective has also been adopted nationally. For example, in order to structurally anchor ESD in regional and local educational landscapes in Germany, the "National Action Plan" (NAP) provides suggestions for appropriate action which is aimed to bring about a reliable structural implementation of ESD within municipalities and federal states. Specifically, the NAP recommends the establishment of cooperation between and networking of formal educational institutions and the informal and non-formal educational sectors [5] (pp. 80-82). It is within this context that the German Federal Ministry of Education and Research directs considerable efforts to push forward this process by running implementation projects and affiliated research at the municipal and regional level. One of these projects is the "ESD Competence

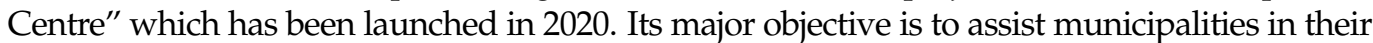
efforts to implement ESD within existing local educational landscapes by combining process support and process evaluation. In order to accomplish this plan, about 48 model municipalities had been identified throughout Germany on the basis of appropriate selection criteria. After contacting the selected municipalities, they have been won for cooperation. Insofar, the aims and scope of the "ESD Competence Centre" provide the background for the network-theory based considerations that are presented subsequently. 
As international and national programs frame the structural anchoring of ESD as an intended process that requires the participation of diverse fields of action such as local governments, schools, extracurricular educational institutions, or non-governmental organizations, implementing ESD can thus be considered as a process of collective action. We thereby regard ESD as a social innovation. Furthermore, we assume that networks play a crucial role in the dissemination and realization of ESD. In this view, we refer to corresponding remarks by Rogers [6]. He emphasizes the importance of subjective evaluations within the dissemination process of new and promising concepts and the essential role of networks as follows:

"In deciding whether or not to adopt an innovation, we all depend mainly on the communicated experience of others much like ourselves who have already adopted. These subjective evaluations of an innovation mainly flow through interpersonal networks." [6] (p. 293)

Hence, networks can be important access gates to information resources. With the considerations of Rogers kept in mind, it should be mentioned that the realization of ESD within existing educational landscapes is not exclusively based on voluntary decisions. Educational landscapes are a conglomeration of educational actors of which at least some are more structured and regulated. This applies, for example, to actors within the formal education sector (schools or vocational trainings) or the municipal administration. These institutions are centrally managed and innovations such as ESD will be purposefully implemented (top-down or fidelitiy approach, see, e.g., [7] (pp. 24-25)). Nonetheless, this does not rule out that such interventions may fail. After all, it cannot be expected that all of those involved are convinced of the benefits or advantages of ESD from the onset and that they rivet all their expertise and efforts to make it a major component of the concerning municipal educational landscape. In this respect, the mutual adaptation approach promises a more realistic perspective. This applies particularly to the fact, that the realization of innovations within the education sector in general (and ESD in particular) cannot be performed strictly according to plan. Instead, they are continuously adapted and changed within this process [7] (pp. 24-25).

The question as to which network structures foster collective action has been addressed theoretically as well as empirically (e.g., [8-10]). However, in regard to ESD research Kolleck et al. [11] (p. 78) criticize "we have so far found theoretically based empirical studies to be missing". Kolleck et al. thereby advocate drawing on network theory-based considerations and concurrently base the framework of their research project on transregional ESD networks. To our knowledge, this project and the contributions related to it (e.g., [12-16]) are among the only broader considerations of networks in the research field on ESD both nationally and internationally. However, they primarily focus on intermunicipal networks, while addressing this level of investigation is undoubtedly justified and highly relevant, the upstream process of ESD implementation has so far remained quite underexposed, i.e., the process of structural anchoring of ESD in municipalities. Hence, a decidedly fundamental investigation of network structural determinants of collective action on ESD implementation can so far be said to be missing. Against this background, the present paper addresses the research question as to which network structures promote the structural anchoring of ESD in municipalities. In the light of this question, we discuss the effects of fundamental network characteristics on ESD implementation, namely network density, bridging ties, and network centrality, and derive a set of corresponding hypotheses in Section 2. Drawing on corresponding theoretical and empirical contributions, we argue that ESD is more likely to be implemented in municipal networks that feature medium density and intersectoral as well as intermunicipal bridges. Additionally, we assume that highly centralized municipal networks promote the structural anchoring of ESD in the initial phase, with decentralized structures being more conducive the more advanced the implementation. Section 3 summarizes our network theory-based considerations and briefly discusses how these hypotheses could be subjected to empirical testing. Thus, this paper aims at compiling implications of network theory that may motivate future research and enable deeper analyses of the process of ESD implementation at a local level. 


\section{Theoretical Considerations}

As already indicated in Section 1, the question of which network structural characteristics influence the structural anchoring of ESD in municipalities is based on the overarching research interest on which and how network structures affect collective action. Network theory contributions as well as empirical studies have addressed this concern and compiled a variety of possible determinants. For example, Bodin and Crona [17] collated network structural properties that influence natural resource governance. Analogously, in the following we focus on some basic network structural properties, i.e., network density, bridging ties, and network centrality, by drawing on corresponding literature streams and discuss how they might favor the structural anchoring of ESD from a network theory perspective. In the discussion presented below, we follow the understanding of social networks suggested by Wasserman and Faust [18] (p. 20): "A social network consists of a finite set or sets of actors and the relation or relations defined on them". Additionally, we make use of basic graph theoretical terms, i.e., "graph" for network, "node" for actor, and "edge" for relation (see, e.g., [19] (p. 21) for an overview).

Alert readers will notice that our exposition goes beyond a purely structural approach in network analysis (e.g., [20]) and makes recourse to certain action-theoretical ideas (e.g., [21,22]). In this regard, several remarks seem in order: First, our paper commits to the fundamental notion of "structural individualism" [21,23,24]. According to this methodological approach, social phenomena should be explained as the outcome or byproduct of figurations of individual actions. However, unlike radical methodological individualism, structural individualism explicitly recognizes and theorizes on the fact that social action is embedded in social structures as well as cultural environments. Structural individualism goes beyond positing a mere duality between structure and action; since actions take place against the background of social structures, this approach allows to conceptualize both the impact of individual agency as well as the effect of structural contingencies on social processes in a transparent theoretical architecture. This methodological approach underlies plenty of seminal contributions towards the sociology of networks which shed light on both the structural impact of network parameters on phenomena such as adherence to social norms [21] and the providion of public goods [25] as well as the emergence of certain network structures [26]. Since collective action can only be understood against the background of a theoretical perspective that explicitly acknowledges the variability of individual and social behavior and, as already indicated in Section 1, the implementation of ESD can be considered as a particular instance of collective action, structural individualism seems like a promising methodological starting point. Second, although we primarily make recourse to literature that assumes some form of rationality among actors, this does not necessarily mean that we commit to this particular narrow conception regarding human behavior. Recent advances in analytical sociology $[27,28]$ clearly demonstrate that structural individualism in general and in particular structural-individualistic research on social networks can work with a great variety of action-theoretical conceptions.

Drawing on this approach, in Section 2.1 we address the question of whether it is conducive to the structural anchoring of ESD to exhaust all possible relations between actors relevant to educational landscapes, or in other words, whether the structural anchoring of ESD requires that all actors involved enter into an exchange with each other. Intuitively, one would probably assume a positive link between the extent of exchange among actors relevant to ESD and the structural anchoring of ESD. However, with reference to the discussion of the nexus between network density and collective action, it can be argued that the extent of contact between actors can hinder the structural anchoring of ESD if a critical value is exceeded. This is due to the assumption that too many relations may undermine the heterogeneity of the fields of action relevant for ESD, a property which in general is considered highly relevant for processes of collective action as it is associated with diversity of information and knowledge. Insofar, the question of whether different fields of action are connected follows on immediately. This aspect is explored in Section 2.2. In this respect, in Section 2.3 we further discuss which properties may strengthen the conduciveness of those relations to the structural anchoring of ESD by relating this question to the individual level. As we will point out, these examinations can be linked to the question of whether the existence of particularly central actors or fields of 
action favors the structural anchoring of ESD at a local level. Intuitively, this may seem plausible when it comes to initiating the implementation process. However, what role does focality play in advanced processes? This nexus is discussed in Section 2.4.

As the reader may have already noticed, we prefer to speak of "structural anchoring" instead of "implementation". The process of policy implementation can basically be described as an effort of corresponding actors to realize a specific policy measure (see, e.g., [29] (p. 84) for a general definition in educational contexts). As reflected in, e.g., the aforementioned multinational policy documents ([1-4]), the process of ESD implementation aims at embedding pertinent concepts and contents into diverse local educational structures, comprising the entirety of a region's formal, informal as well as non-formal institutions and offerings—or, as we call it, "educational landscapes", - via a long-term oriented institutionalization. To emphasize the structural dimension of the target level of ESD implementation, we mainly use the term "structural anchoring" in the following.

\subsection{Density of Municipal Networks}

In general, it is assumed that network density, i.e., the ratio of actual relations to all potential relations, promotes collective action (see, e.g., [17]) (pp. 367-368). This assumption can be traced back to Coleman [21,30]. He argues that in rather closed networks, i.e., in networks of high density, information is made accessible at low cost. For example, it is assumed that an actor embedded in a rather dense network can contextualize new information as well as subject-specific knowledge and evaluate its relevance and reliability [31,32]. Moreover, according to Coleman, closed networks enable the establishment of social control mechanisms and hence reduce uncertainty among actors. Thus, in dense networks trust and reciprocity are more likely to develop due to an increase in communication opportunities [33,34], which positively affect the willingness to cooperate [35,36]. However, with regards to the impact of network density on collective action empirical evidence paints a more nuanced picture, while some findings support the assumption that denser networks promote collective action (e.g., [37]), some studies indicate a rather inverted u-shaped relationship between network density and collective action (e.g., [9]), or network density and the effectiveness of collective action (e.g., [38]). There are analytical as well as theoretical considerations that may explain the latter nexus. First, it is plausible to state that individual resources which are necessary for establishing and maintaining social contacts, especially time, are limited, so that the number of interpersonal relationships relevant for collective action is de facto determined. Especially for larger networks it can thus be assumed that the analytically expected maximum, i.e., a network density of 1 , and the maximum value achieved in reality diverge. Second, the aforementioned relationship can also be attributed to the fact that in very dense networks redundant information tends to circulate (e.g., [31,39]). Furthermore, pronounced forms of conformity and loyalty may prevent innovative and effective cooperation with others due to high social pressure (e.g., [40-43]). Hence, the argument for a generally positive influence of network density on collective action can be countered by the notion that too-dense networks promote homogeneity and social closure and consequently even have a disintegrating effect (e.g., [39]). Very dense networks may thus be associated with a lower adaptability (e.g., [44]), a basic property that is especially elementary for processes of collective action.

In the research on ESD, Kolleck [12] initially considered densities of municipal ESD networks. However, since Kolleck analyzed municipalities of similar ESD implementation levels, it remains unclear whether and to what extent municipalities of higher ESD implementation levels differ from municipalities of lower ESD implementation levels. Against the background of the foregoing theoretical discussion and empirical findings, an inverted u-shaped relationship between network density and structural anchoring of ESD can be expected. 
Hypothesis 1 (H1). ESD is most likely to be structurally anchored in municipalities of medium network density.

As indicated above, it can furthermore be assumed that network density is negatively associated with network size. Generally, it can be expected that the larger a network is, the fewer opportunities there are for the formation of social relationships. For example, because in larger networks responsibilities and tasks are more differentiated, so that some relationships are unnecessary and hence are less likely to be established, or just because actors simply meet less frequently. This is already reflected in the formal definition of network density $d$, which indicates the ratio between the number of actual relations $m$ and the number of all possible relations $\frac{n(n-1)}{2}$ [18] (p. 101), i.e.,

$$
d=\frac{m}{\frac{n(n-1)}{2}}=\frac{2 m}{n(n-1)}
$$

with $d \in[0,1]$. (Here we refer to the density of undirected graphs $d\left(G_{u}\right)$. However, the following argument also holds for directed graphs $G_{d}$, in which analytically the number of possible relations is indicated by $n(n-1)$, so that $d\left(G_{d}\right)=\frac{m}{n(n-1)}$.) Due to the abovementioned argument of limited individual resources, one can assume the average number of actual relations $\bar{m}_{i}$ a node $i=1, \ldots, k$ can hold to be fixed. Hence, it can be argued that network density should decrease as network size increases (see, e.g., [45] (p. 204), [46] (p. 49)). Empirically, Kolleck's findings can be interpreted as an indication of this hypothesis since increasing network size [12] (p. 316, Table 1) is accompanied by lower network density [12] (p. 318, Figure 2). Therefore, the effect described in H1 can be expected to be moderated by the size of the municipal networks.

Hypothesis 2 (H2). The larger a municipality, the lower its network density.

\subsection{Linkages between Fields of Action}

As already mentioned in the previous discussion of network density, another facilitating factor considered in the literature on networks and collective action is heterogeneity, as it is associated with diversity of information and knowledge. (While network density may be helpful to initially describe social networks, it is not considered to be an appropriate indicator for path structure. This is because network density does not provide information on whether and to what extent a network is composed of sub-networks, so-called clusters, and how far these are interconnected (see, e.g., [46,47]), i.e., network density does not indicate the degree of heterogeneity in a network.) Due to spatial distance, differentiation processes, and the aforementioned limitation of individual resources, the formation of clusters can generally be considered as inevitable [17] (p. 368). The literature on network theory argues that the existence of clusters is functional for cooperation and joint action in networks-but only to a certain extent, i.e., a general trade-off is assumed: While too much clustering leads to group biases and hence hinders cooperation between clusters [48], networks without clusters lack diversity, which is reflected, for example, in the dominance of redundant information (e.g., [39,44]). In this context, the combination of the existence of clusters and the interconnection of those clusters should enable interindividual information exchange in complex networks. Hence, the structural anchoring of ESD in local educational landscapes should be facilitated by, firstly, the existence of clusters, i.e., various ESD-relevant fields of action, within municipal networks and, secondly, the interconnection of these fields of action. As already mentioned in Section 1, various institutions are thought to be involved in the structural anchoring of ESD in local educational landscapes, e.g., local governments, the school sector, extracurricular educational institutions, non-governmental organizations (NGOs), and business enterprises (see, e.g., [12]). As it can be assumed that those institutions exist independently of ESD, in the following we focus on the second premise. Hence, the question arises as to how these fields of action are embedded in 
municipal networks, i.e., how those fields of action are interconnected. Thus, the concept of a bridge [39] (pp. 1364-1365) is another central aspect for the investigation of the structural anchoring of ESD:

(Local) Bridge. A local bridge is an edge that represents the shortest path between two nodes otherwise indirectly connected by at least three edges. A bridge is an edge that represents the only path between two otherwise unconnected nodes.

(Local) Bridges thus promote the reach of new types of information on the one hand and the formation or strengthening of trust and willingness to cooperate between otherwise unconnected or indirectly connected actors on the other. This assumption is supported by empirical evidence which indicates that (local) bridges have a positive effect on the adaptation of new ideas and the potential to solve problems [21,39,44] (see also [17] (pp. 369-370) for a brief compilation of empirical findings).

The degree of ESD implementation in a municipality should thus depend on whether the sectoral clusters, i.e., fields of action, are interconnected. Hence, a positive correlation can be expected. In addition, it can be assumed that intermunicipal relationships have a positive effect on the implementation of ESD "on the ground" as they enable the exchange of experiences and knowledge in the field of structural anchoring of ESD between municipalities. Such positive or negative examples can in turn feed into the planning and expansion of municipal educational landscapes with an ESD focus.

Hypothesis 3 (H3). The more intersectoral bridges in a municipality, the more likely the structural anchoring of ESD in this municipality.

Hypothesis 4 (H4). The more intermunicipal bridges between municipalities, the more likely the structural anchoring of ESD in those municipalities.

The effect of intersectoral and intermunicipal bridges is moderated by the social embeddedness of the actors between whom these bridges span because it must be assumed that they are informed about the processes in certain clusters, i.e., that they are embedded in different sectoral clusters. This assumption can be illustrated as follows: Ego and alter are part of network $a$. An edge spans between ego and alter. No other edges to members of network $a$ extend from ego and alter, i.e., both maintain exactly one relation, namely that to each other. The relation between ego and alter is by definition a bridge, but the information that ego and alter exchange does not reach any other actor of network $a$ or another network $b$. Intuitively, one would speak of the bridge between ego and alter as having no relevance at the network level [19] (pp. 65-66). This idea is contained in the concept of edge betweenness [19] (p. 67). For collective action processes that require interorganizational cooperation, bridges are thus all the more important the more cluster-specific information is disseminated across them, i.e., when they span the formal boundaries of organizations. Therefore, bridges do not per se contribute to collective action of ESD relevant fields of action in a municipality. In this respect, it can be assumed that intersectoral as well as intermunicipal bridges are only relevant for the structural anchoring of ESD in municipal educational landscapes if the information traded via these bridges is also disseminated in the municipalities. Therefore it can be assumed that the betweenness of a bridge moderates the effects on structural anchoring of ESD as formulated in $\mathrm{H} 3$ and $\mathrm{H} 4$.

Hypothesis 5 (H5). The higher the betweenness of a bridge, the stronger the effect of this bridge on the structural anchoring of ESD.

\subsection{Properties of Bridging Ties}

To date, we have argued that linking heterogeneous fields of action is of central importance for the structural anchoring of ESD in municipalities. In a further step, we now want to address the question of which characteristics of bridging ties favor this collective goal. In this context, we focus on dyadic relations which enable the exchange 
of sector- or community-specific information. At the individual level, the exchange of cluster-specific information can be conceptualized as social exchange. Such situations are subject to double contingency, i.e., actors are strategically interdependent: The outcome of ego's action depends on alter's action and vice versa [49]. Because of the uncertainty about the other's behavior, social exchange relations are accompanied by a trust or cooperation problem [21,50]. Within clusters-in our case: within ESD-relevant fields of action-the extent of these uncertainties should be rather low, since a large part of the cooperation within these fields of action is regulated by work contracts, the assignment of responsibilities, and hierarchization. In addition, work environments, organizations, or associations, i.e., the fields of action in the context of ESD, can be conceptualized as so-called foci [51]. A focus describes "a social, psychological, legal, or physical entity around which joint activities are organized" [51] (p. 1016) and functions as a reference along which clusters are formed. Thus, a shared focus typically increases the likelihood of interindividual relationships and, depending on its binding nature, can strengthen relationships [51] (pp. 1019, 1024). Hence, it can be argued that a shared focus reduces uncertainty and thus the risk for trust and cooperation problems within clusters. Therefore it can be assumed that uncertainties regarding trustworthiness and willingness to cooperate primarily occur in interactions between actors from different ESD-relevant fields of action. (Note that the expansion of municipal ESD landscapes can be interpreted as an attempt to establish a common focus that unifies the activities of "natural" clusters mentioned before, such as organizations).

Against this background, the question now is which properties of bridging ties can resolve the trust and cooperation problem inherent in them and thus enable the exchange of cluster-specific information. In general, Granovetter's work is considered to have influenced the analysis of bridging ties in networks, especially their contribution "Strength of Weak Ties" [39]. In this paper, he shows, with reference to the principle of strong triadic closure (The strong triadic closure property states: If there is a strong tie $s$ between $A$ and $B$ and a strong tie $s$ between $A$ and $C$, there is at least a weak tie $w$ between $B$ and $C$ [19] (p. 49).), that strong ties cannot fulfill the network structural function of a bridge and concludes that all bridges are weak ties [39] (p. 1364). According to Granovetter [39] (p. 1366), weak ties thus enable the connection of different actors, hence clusters, as well as the formation of larger, heterogeneous networks, and consequently increase the speed and reach of dissemination of new information. He therefore concludes that weak ties promote social cohesion, while strong ties tend toward social closure and disintegration [39] (p. 1378) (for a critical discussion of this assumption see, e.g., [52]). Whether weak ties drive the diffusion process of novel and relevant information has been and continues to be critically debated. Empirically, contradictory findings for Granovetter's hypothesis can be found [53] (p. 1931). For example, Larson [54] shows that weak ties and adding such ties to pre-existing networks might even slow down information diffusion. Even Granovetter himself does not exclude the importance of strong ties [52] (pp. 209-213). However, what is meant by "tie strength"? Theoretical and empirical works on networks mostly define the quality of ties as a "combination of the amount of time, the emotional intensity, the intimacy (mutual confiding), and the reciprocal services" [39] (p. 1361) or use one indicator from that list, mostly the amount of time. Krackhardt [55] (pp. 216-217) points out the problem of the indeterminacy of tie strength, primarily because it is unclear whether these four indicators equally account for it. Thus, it could be determined whether ties are stronger or weaker than others; however, what exactly constitutes a strong or weak tie remains vague. In light of this problem, rather than focusing on tie strength as a property of bridging ties, we will approach the upstream analysis by focusing on the trust and cooperation problem inherent in these bridges.

Traditionally, game theory deals with situations of strategic interdependence and the solution of associated trust and cooperation problems. One central objective of game theory is to model and analyze strategic interactions, in which individual and collective rationality may diverge. In general, this incongruity is explained by the fact that ego's best responses to alter's best responses, and vice versa, maximize the respective individual utility, but do 
not result in a Pareto optimal state. The trust game and the prisoner's dilemma represent classical models of the trust and cooperation problem, respectively. These games lead to outcomes, in which neither of the players places trust or cooperates, although both would be better off doing so. Hence, the question arises as to under which circumstances trust or cooperation can prevail as a strategy. In this respect, Axelrod [22] states that cooperation may occur when future interactions can not be excluded, i.e., in iterated games:

"What makes it possible for cooperation to emerge is the fact that the players might meet again. This possibility means that the choices made today not only determine the outcome of this move, but can also influence the later choices of the players. The future can therefore cast a shadow back upon the present and thereby affect the current strategic situation." [22] (p. 12)

Therefore, a prerequisite for mutual cooperation is that ego makes her/his own action in round $t$ dependent on the anticipated decision of alter in round $t+1$, and vice versa. Consequently, the importance that ego and alter attach to the future, the so-called shadow of the future, must be sufficiently large because only then is the threat of possible sanctioning unilateral defection credible [22] (p. 126). Hence, one of Axelrod's suggestions for promoting mutual cooperation is to increase the shadow of the future. According to Axelrod, longevity, i.e., the mutual expectation that the same individuals will interact indefinitely, and high frequency, i.e., shortening the time intervals between interactions, increase the value of future moves to the present move [22] (pp. 129-132). Empirically, the assumption that the extent of mutual cooperation is greater in durable and frequent interactions than in short-term and infrequent interactions is generally confirmed (see, e.g., $[22,56,57])$.

Against this background, the individual willingness to share information with each other should depend on the shadow of the future of these interactions. According to Axelrod, this shadow of the future increases with long-term and frequent interactions. With regards to the characteristics of bridging ties, it can therefore be assumed that longevity and frequency promote cooperation, and hence the exchange of cluster-specific information, between actors from different fields of action. Qualitative analyses indicate this assumption (e.g., [16]). It can therefore be assumed that long-term nature and frequency of bridging ties moderate the effect described in $\mathrm{H} 3$ and $\mathrm{H} 4$, respectively.

Hypothesis 6 (H6). The higher the longevity and frequency of a bridge, the stronger the effect of this bridge on the structural anchoring of ESD.

\subsection{Centrality of Municipal Networks}

Another relevant network characteristic that may affect collective action is closely related to the concept of bridging ties, i.e., centrality. Highly centralized networks can be described as networks in which the centrality of actors varies greatly within that network [58]. Actors can be considered particularly central if their relations bridge gaps because those "structural holes capture the condition directly responsible for the information benefits. The task for a strategic player building an efficient-effective network is to focus resources on the maintenance of bridge ties" [44] (p. 30). Hence, it is profitable for ego to be embedded in a network that has many structural holes. Ego has an incentive to bridge structural holes and thus to hold a specific network position since this is accompanied by high social capital as well as comparative advantages, namely information and control advantages. As a broker, ego has exclusive connections to different groups that are denied to non-brokers and therefore disposes of non-redundant information for clusters connected by ego. Ego thus knows, for example, about cluster-specific logics, resources, and interests, as well as differences within a network. This enables ego to assess which negotiators are worth bringing together and which information is relevant to which individuals. This increases ego's value as a contact person. Brokers are therefore more likely to formulate and communicate innovative ideas or to initiate projects [59] (p. 349). Accordingly, it can be assumed that central actors are particularly likely to initiate collaborative projects. For example, 
Simpson et al. [60] argue that status-higher actors-and brokers can be characterized as such, since they have higher social capital than non-brokers, as explained above-are more able to contribute to solving the initial problem of collective action, namely the initiation of collective action, than status-lower actors, who then imitate the initial actions of statushigher actors and thus initiate a diffusion process across the board. At the network level, it can thus be assumed that centralized networks favor the accomplishment of collective tasks, especially in the initial phase. However, as the share of contributing actors increases over time, it can be expected that the degree of centrality decreases. Empirical studies provide evidence for this assumption and suggest that more decentralized network structures favor the solution of particularly long-term collective tasks [17] (p. 371) (see also, e.g., [61]).

Thus, it is plausible to assume that network centrality influences the structural anchoring of ESD in local educational landscapes as described above: It is conceivable that, for example, local government actors initiate the development of ESD-focused educational landscapes, but that over time actors from different fields of action, such as schools, informal and non-formal educational institutions, adapt corresponding measures. Hence, intersectoral cooperation develops in this regard, leading to a decrease of the centrality of local government actors. Taking the temporal dimension into account would thus help to paint a more nuanced picture of the relative centrality and influence of certain areas of action, especially in view of previous findings (e.g., [12]).

Hypothesis 7 (H7). In the initial phase, high network centrality promotes the structural anchoring of ESD in a municipality.

Hypothesis 8 (H8). The more advanced the structural anchoring of ESD in a municipality, the more conducive lower network centrality.

\section{Conclusions and Outlook}

In this paper, we discussed which network structures promote the structural anchoring of ESD in municipalities, while previous work has focused primarily on transregional implementation processes (e.g., [12,13]), we advocated addressing the upstream process of structurally anchoring ESD within municipal educational landscapes. We therefore presented an initial discussion of the effects of features of municipal network structures deemed particularly relevant for ESD implementation. Against the background of corresponding theoretical and empirical contributions, we argued that ESD is more likely to be implemented in municipal networks that feature medium density and intersectoral as well as intermunicipal bridges. Additionally, we assumed that highly centralized municipal networks promote the structural anchoring of ESD in the initial phase, with decentralized structures being more conducive the more advanced the implementation. Our aim was to present a theoretical treatise that may motivate further research on ESD implementation and thus to complement previous work, also in consideration of the insufficient theoretical foundation attributed to this field by Kolleck et al. [11] (p. 78). In other words: Municipal structures which allow actors from various fields of action and other municipalities to communicate with each other and exchange their specific ideas and experiences on a regular basis should foster ESD implementation. Furthermore, focal actors or fields of action may be advantageous for initiating ESD implementation in a municipality, but should lose significance as adaptation processes increase over time.

Admittedly, our contribution has some limitations which in the following we want to address. First, a more in-depth analysis of possible factors underlying these network structures was not undertaken within the scope of this paper. For example, with regards to the discussion of bridging ties it can be argued that the individual motivation to exchange cluster-specific information also depends on competitive structures (see, e.g., [54]), i.e., the perception of the goal of ESD implementation as a competitive situation between municipalities by the participants or competition between fields of action within municipalities may influence the payoff structure in the sense of Axelrod [22] (pp. 133-134) in such a way 
that the probability of exchanging information between municipalities or fields of action is reduced. The network-structural focus of the present contribution could therefore be complemented with a further elaboration of facilitating and inhibiting factors for cooperation (as for instance conducted by Kolleck and Bormann [16]), or with an analysis of prevailing governance structures.

Second, as our paper is a conceptual contribution we cannot provide any empirical results needed to derive practical implications or specific suggestions. For the time being, we would like to draw attention to two aspects concerning the procedure of empirical testing. On the one hand, it should be pointed out that the object of this contribution, i.e., the structural anchoring of ESD in municipal educational landscapes, was not explained in detail. Depending on the operationalization of the dependent variable, the hypotheses stated may take on definitional features; e.g., if interactions between fields of action are included in the conception of the expansion of structural anchoring of ESD in municipal educational landscapes. In order to approach the object of investigation in a first step and consequently not to prematurely limit the applicability of the hypotheses formulated here, we have refrained from elaborating an all-encompassing definition of the multidimensional concept of the structural anchoring of ESD. Further theoretical work and especially empirical studies testing our or similar hypotheses should definitely take this point into account. This leads us to the second, a far more delicate point, namely the question of empirical testability. A decisive examination of the hypotheses derived here requires complete, or sociocentric, network data from municipalities of different levels of ESD implementation. This is a major challenge, since, strictly speaking, drawing random samples in this case is not sufficient. For example, in order to accurately test the hypotheses regarding bridges, it is necessary to ensure that the bridges identified are actual bridges and thus to rule out the possibility of characterizing them as such due to missing data. In our view, such an approach would further deepen and advance the analysis of the conditions for the structural anchoring of ESD and help to close the gap of theory-based research in this field. In this respect, by providing a theoretical discussion of the question of which network structures promote the structural anchoring of ESD in municipalities and elaborating corresponding hypotheses we hope that this paper initiates and stimulates future research projects that will eventually lead to the derivation of practical implications for the structural anchoring of ESD.

Author Contributions: Conceptualization, A.-L.S.; writing—original draft preparation, A.-L.S.; writing-review and editing, A.-L.S., R.G. and D.R.; supervision, D.R.; funding acquisition, D.R. This paper builds on an earlier, rather practice-oriented contribution [62] and elaborates implications of network theory by deriving testable hypotheses for an empirical-analytical consideration of the research object. All authors have read and agreed to the published version of the manuscript.

Funding: We thank the Federal Ministry of Education and Research for financial support within the project "BNE-Kompetenzzentrum" (grant number 01JE20C). The funder had no role in the writing of the manuscript.

Conflicts of Interest: The authors declare no conflict of interest.

\section{References}

1. UNESCO. UNESCO Roadmap for Implementing the Global Action Programme on Education for Sustainable Development; UNESCO: Paris, France, 2014.

2. UNESCO. Education for Sustainable Development. A Roadmap; UNESCO: Paris, France, 2020.

3. UN. Report of the World Summit on Sustainable Development. Johannesburg, South Africa, 26 August-4 September 2002; UN: New York, NY, USA, 2002.

4. UN. Report of the United Nations Conference on Environment and Development. Rio de Janeiro, 3-14 June 1992. Volume I. Resolutions Adopted by the Conference; UN: New York, NY, USA, 1993.

5. National Platform on Education for Sustainable Development. National Action Plan on Education for Sustainable Development. The German Contribution to the UNESCO Global Action Programme; National Platform on Education for Sustainable Development: Berlin, Germany, 2019.

6. $\quad$ Rogers, E.M. Diffusion of Innovations, 3rd ed.; Free Press: New York, NY, USA, 1983. 
7. $\quad$ Singer-Brodowski, M.; Etzkorn, N.; Grapentin-Rimek, T. Diffusion und Hebelpunkte von Bildung für nachhaltige Entwicklung im deutschen Bildungssystem. In Pfade der Transformation. Die Verbreitung von Bildung für Nachhaltige Entwicklung im Deutschen Bildungssystem; Singer-Brodowski, M., Etzkorn, N., Grapentin-Rimek, T., Eds.; Barbara Budrich: Opladen, Germany; Toronto, ON, Canada, 2019; pp. 15-48.

8. Siegel, D.A. Social Networks and Collective Action. Am. J. Pol. Sci. 2009, 53, 122-138.

9. Gould, R.V. Collective Action and Network Structure. Am. Sociol. Rev. 1993, 58, 182-196. [CrossRef]

10. Chwe, M.S.-Y. Structure and Strategy in Collective Action. Am. J. Sociol. 1999, 105, 128-156. [CrossRef]

11. Kolleck, N.; de Haan, G.; Fischbach, R. Social Networks for Path Creation: Education for Sustainable Development Matters. J. Futur. Stud. 2011, 15, 77-92. [CrossRef]

12. Kolleck, N. Uncovering Influence Through Social Network Analysis: The Role of Schools in Education for Sustainable Development. J. Educ. Policy 2016, 31, 308-329.

13. Kolleck, N. The Emergence of a Global Innovation in Education. Diffusing Education for Sustainable Development Through Social Networks. Environ. Educ. Res. 2019, 25, 1635-1653. [CrossRef]

14. Kolleck, N. Innovations Through Networks: Understanding the Role of Social Relations for Educational Innovations. Z. Erzieh. 2014, 17, 47-64. [CrossRef]

15. Kolleck, N.; Jörgens, H.; Well, M. Levels of Governance in Policy Innovation Cycles in Community Education: The Cases of Education for Sustainable Development and Climate Change Education. Sustainability 2017, 9, 1966-1966. [CrossRef]

16. Kolleck, N.; Bormann, I. Analyzing Trust in Innovation Networks: Combining Quantitative and Qualitative Techniques of Social Network Analysis. Z. Erzieh. 2014, 17, 9-27. [CrossRef]

17. Bodin, Ö.; Crona, B.I. The Role of Social Networks in Natural Resource Governance: What Relational Patterns Make a Difference. Glob. Environ. Chang. 2009, 14, 366-374. [CrossRef]

18. Wasserman, S.; Faust, K. Social Network Analysis. Methods and Applications. Structural Analysis in the Social Sciences; Cambridge University Press: Cambridge, UK, 1994; Volume 8. [CrossRef]

19. Easley, D.; Kleinberg, J. Networks, Crowds, and Markets: Reasoning about a Highly Connected World; Cambridge University Press: New York, NY, USA, 2010. [CrossRef]

20. White, H.C. Identity and Control: A Structural Theory of Social Action; Princeton University Press: Princeton, NJ, USA, 1992.

21. Coleman, J.S. Foundations of Social Theory; The Belknap Press of Harvard University Press: Cambridge, UK, 1990.

22. Axelrod, R. The Evolution of Cooperation; Basic Books: New York, NY, USA, 1984.

23. Wippler, R. The Structural-Individualistic Approach in Dutch Sociology. Neth. J. Sociol. 1978, 4, $135-155$.

24. Lindenberg, S. 1992: The Method of Decreasing Abstraction. In Rational Choice. Advocacy and Critique; Coleman, J.S., Fararo, T.J., Eds.; SAGE: London, UK, 1992; pp. 4-20.

25. Gould, R.V. The Origins of Status Hierarchies: A Formal Theory and Empirical Test. Am. J. Sociol. 2002, 107, 1143-1178.

26. Buskens, V.; van de Rijt, A. Dynamics of Networks if Everyone Strives for Structural Holes. Am. J. Sociol. 2008, $114,371-407$.

27. Hedström, P.; Bearman, P. What is Analytical Sociology All About? An Introductory Essay. In The Oxford Handbook of Analytical Sociology; Hedström, P., Bearman, P., Eds.; Oxford University Press: Oxford, UK, 2011; pp. 3-24. [CrossRef]

28. Manzo, G. Data, Generative Models, and Mechanisms: More on the Principles of Analytical Sociology. In Analytical Sociology: Actions and Networks; Manzo, G., Ed.; Wiley: Chichester, UK, 2014; pp. 4-52. [CrossRef]

29. Fullan, M. The NEW Meaning of Educational Change, 4th ed.; Teachers College Press: New York, NY, USA; London, UK, 2007.

30. Coleman, J.S. Social Capital in the Creation of Human Capital. Am. J. Sociol. 1988, 94, S95-S120.

31. Gilsing, V.; Nooteboom, B. Density and Strength of Ties in Innovation Networks: An Analysis of Multimedia and Biotechnology. Eur. Manag. Rev. 2005, 2, 179-197.

32. Leonard-Barton, D. Interpersonal Communication Patterns Among Swedish and Boston-Area Entrepreneurs. Res. Policy 1984, 13, 101-114. [CrossRef]

33. Axelrod, R. The Dissemination of Culture: A Model with Local Convergence and Global Polarization. J. Confl. Resolut. 1997, 41, 203-226. [CrossRef]

34. Putnam, R.D.; Leonardi, R.; Nanetti, R.Y. Making Democracy Work. Civic Traditions in Modern Italy; Princeton University Press: Princeton, NJ, USA, 1993. [CrossRef]

35. Hagedoorn, J.; Duysters, G. Learning in Dynamic Inter-Firm Networks: The Efficacy of Multiple Contacts. Organ. Stud. 2002, 23, 525-548. [CrossRef]

36. Gulati, R. Does Familiarity Breed Trust? The Implications of Repeated Ties for Contractual Choice in Alliances. Acad. Manag. J. 1995, 38, 85-112.

37. Marwell, G.; Oliver, P.E.; Prahl, R. Social Networks and Collective Action: A Theory of the Critical Mass. III. Am. J. Sociol. 1988, 94, 502-534. [CrossRef]

38. Oh, H.; Chung, M.-H.; Labianca, G. Group Social Capital and Group Effectiveness: The Role of Informal Socializing Ties. Acad. Manag. J. 2004, 47, 860-875.

39. Granovetter, M.S. The Strength of Weak Ties. Am. J. Sociol. 1973, 78, 1360-1380. [CrossRef]

40. Duysters, G.; Lemmens, C. Alliance Group Formation: Enabling and Constraining Effects of Embeddedness and Social Capital in Strategic Technology Alliance Networks. Stud. Manag. Organ. 2003, 33, 49-68. [CrossRef]

41. Gulati, R.; Nohria, N.; Zaheer, A. Strategic Networks. Strateg. Manag. J. 2000, 21, 203-215. [CrossRef] 
42. Nooteboom, B. Inter-Firm Alliances. Analysis and Design; Routledge: London, UK; New York, NY, USA, 1999. [CrossRef]

43. Kraatz, M.S. Learning by Association? Interorganizational Networks and Adaptation to Environmental Change. Acad. Manag. J. 1998, 41, 621-643. [CrossRef]

44. Burt, R.S. Structural Holes. The Social Structure of Competition; Harvard University Press: Cambridge, UK; London, UK, 1992.

45. Faust, K. Comparing Social Networks: Size, Density, and Local Structure. Metod. Zv. 2006, 3, $185-216$.

46. Friedkin, N.E. The Development of Structure in Random Networks: An Analysis of the Effects of Increasing Network Density on Five Measures of Structure. Soc. Netw. 1981, 3, 41-52.

47. Moody, J.; Coleman, J. Clustering and Cohesion in Networks: Concepts and Measures. In International Encyclopedia of the Social E Behavioral Sciences, 2nd ed.; Wright, J.D., Ed.; Elsevier: New York, NY, USA, 2015; pp. 906-912. [CrossRef]

48. Borgatti, S.P.; Foster, P.C. The Network Paradigm in Organizational Research: A Review and Typology. J. Manag. 2003, 29, 991-1013. [CrossRef]

49. von Neumann, J.; Morgenstern, O. Theory of Games and Economic Behavior; Princeton University Press: Princeton, NJ, USA, 1944.

50. Dasgupta, P. Trust as a Commodity. In Trust. Making and Breaking Cooperative Relations; Gambetta, D., Ed.; Blackwell: Oxford, UK; Cambridge, UK, 1988; pp. 49-72.

51. Feld, S.L. The Focused Organization of Social Ties. Am. J. Sociol. 1981, 86, 1015-1035.

52. Granovetter, M.S. The Strength of Weak Ties: A Network Theory Revisited. Sociol. Theory 1983, 1, $201-233$.

53. Aral, S. The Future of Weak Ties. Am. J. Sociol. 2016, 121, 1931-1939. [CrossRef]

54. Larson, J.M. The Weakness of Weak Ties for Novel Information Diffusion. Appl. Netw. Sci. 2017, 2, 14. [CrossRef]

55. Krackhardt, D. The Strength of Strong Ties: The Importance of Philos in Organizations. In Networks and Organizations: Structure, Form, and Action; Nohria, N., Eccles, R.G., Eds.; Harvard Business School Press: Boston, MA, USA, 1992; pp. 216-239. [CrossRef]

56. Bó, P.D. Cooperation under the Shadow of the Future: Experimental Evidence from Infinitely Repeated Games. Am. Econ. Rev. 2005, 95, 1591-1604. [CrossRef] [PubMed]

57. Heide, J.B.; Miner, A.S. The Shadow of the Future: Effects of Anticipated Interaction and Frequency of Contact on Buyer-Seller Cooperation. Acad. Manag. J. 1992, 35, 265-291.

58. Freeman, L.C. Centrality in Social Networks Conceptual Clarification. Soc. Netw. 1978-1979, 1, 215-239. [CrossRef]

59. Burt, R.S. Structural Holes and Good Ideas. Am. J. Sociol. 2004, 110, 349-399. [CrossRef]

60. Simpson, B.; Willer, R.; Ridgeway, C.L. Status Hierarchies and the Organization of Collective Action. Sociol. Theory 2012, 30, 149-166. [CrossRef]

61. Prell, C.; Hubacek, K.; Reed, M. Stakeholder Analysis and Social Network Analysis in Natural Resource Management. Soc. Nat. Resour. 2009, 22, 501-518. [CrossRef]

62. Schönheit, A.-L. Kommunale Netzwerkstrukturen und die Verankerung von Bildung für nachhaltige Entwicklung. UFZ Discuss. Paper 2021, 7/2021, 128-148. [CrossRef] 